\title{
Sensitive and quantitative probing of pseudouridine modification in mRNA and long noncoding RNA
}

\author{
WEN ZHANG, ${ }^{1}$ MATTHEW J. ECKWAHL, ${ }^{2}$ KATHERINE I. ZHOU, ${ }^{2}$ and TAO PAN ${ }^{2}$ \\ ${ }^{1}$ Department of Chemistry, ${ }^{2}$ Department of Biochemistry and Molecular Biology, University of Chicago, Chicago, Illinois 60637, USA
}

\begin{abstract}
Pseudouridine $(\Psi)$ is the most abundant RNA modification in cellular RNA present in tRNA/rRNA/snRNA and also in mRNA and long noncoding RNA (IncRNA). Elucidation of $\Psi$ function in $m R N A /$ IncRNA requires mapping and quantitative assessment of its modification fraction at single-base resolution. The most widely used $\Psi$ mapping method for mRNA/lncRNA relies on its reaction with $N$-Cyclohexyl- $N^{\prime}$-(2-morpholinoethyl)carbodiimide (CMC), forming an adduct with the $\Psi$ base in RNA that is detectable by reverse transcription (RT) stops. However, this method has not produced consistent $\Psi$ maps in mRNAs; furthermore, available protocols do not lend confidence to the estimation of $\Psi$ fraction at specific sites, which is a crucial parameter for investigating the biological relevance of mRNA modifications. Here we develop a quantitative RT-PCR based method that can detect and quantify the modification fraction of target $\Psi$ sites in mRNA/IncRNA, termed CMC-RT and ligation assisted PCR analysis of $\Psi$ modification (CLAP). The method still relies on RT stop at a CMC- $\Psi$ site, but uses site-specific ligation and PCR to generate two distinct PCR products in the same sample, corresponding to the modified and unmodified site, that are visualized by gel electrophoresis. CLAP not only requires a small amount of cellular RNA to validate $\Psi$ sites but also determines the $\Psi$ fraction semiquantitatively at target sites in mRNA/lncRNA. We determined the $\Psi$ status of four mRNA sites and one IncRNA site whose modification fractions range from $30 \%$ to $84 \%$ in three human cell lines. Our method enables precise mapping and assessment of $\Psi$ modification levels in low abundance cellular RNAs.
\end{abstract}

Keywords: pseudouridine; mRNA; RT-PCR

\section{INTRODUCTION}

More than 170 types of RNA modifications have been identified in biology (Delaunay and Frye 2019). Pseudouridine $(\Psi)$ was the first RNA modification discovered and is also the most abundant in cellular RNA (Charette and Gray 2000). $\Psi$ is the 5-ribosyl isomer of uridine (U) with a carbon-carbon (C5-C1') bond in place of the nitrogen-carbon (N1-C1') bond between the base and the sugar backbone. The $\mathrm{C}-\mathrm{C}$ bond gives $\Psi$ more rotational freedom and conformational flexibility (Charette and Gray 2000; Ge and Yu 2013). In addition, $\Psi$ has an extra hydrogen bond donor at the $\mathrm{N} 1$ position. $\Psi$ modification has been shown to rigidify RNA structure through hydrogen bonding to the ribosephosphate backbone and enhance RNA stacking. $\Psi$ in rRNA and tRNA has been shown to fine-tune and stabilize the regional structure and help maintain their functions in mRNA decoding, ribosome assembly, processing, and translation (Charette and Gray 2000; Ge and Yu 2013; Li et al. 2016; Rintala-Dempsey and Kothe 2017). $\Psi$ in

Corresponding author: taopan@uchicago.edu

Article is online at http://www.rnajournal.org/cgi/doi/10.1261/rna. 072124.119.
snRNA has been shown to enhance spliceosomal RNApre-mRNA interaction to facilitate splicing regulation (Wu et al. 2011, 2016). A recent study unveiled a role for pseudouridylated tRNA fragments in translational control of stem cells (Guzzi et al. 2018).

$\Psi$ has also been found in mRNA and long noncoding RNA (IncRNA) (Carlile et al. 2014; Lovejoy et al. 2014; Schwartz et al. 2014; Li et al. 2015). $\Psi$ is among the major mRNA modifications identified; its overall abundance as measured by mass spectrometry (Li et al. 2015) is second only to $N^{6}$-methyladenosine $\left(m^{6} \mathrm{~A}\right)$. Additional $\Psi$ modifications appear in the transcriptome under stress (Carlile et al. 2014; Schwartz et al. 2014), indicating that it is dynamic and plays multiple roles in the regulation of gene expression in a cell type- and cell state-dependent manner. A well-defined function of $\Psi$ in mRNA is to enable efficient stop codon readthrough (Karijolich and Yu 2011).

(C) 2019 Zhang et al. This article is distributed exclusively by the RNA Society for the first 12 months after the full-issue publication date (see http://rnajournal.cshlp.org/site/misc/terms.xhtml). After 12 months, it is available under a Creative Commons License (Attribution-NonCommercial 4.0 International), as described at http:// creativecommons.org/licenses/by-nc/4.0/. 
To elucidate the biological function of $\Psi$ in mRNA/ IncRNA, it is crucial to validate the location of $\Psi$ sites in low abundance RNA species. Like all mRNA/IncRNA modifications studied so far, the $\Psi$ modification fraction at each mRNA site may also be highly variable and likely plays a role in regulating its function. At this time, all highthroughput sequencing methods rely on the reaction of $N$-cyclohexyl- $N^{\prime}$-(2-morpholinoethyl)carbodiimide (CMC) with $\Psi$. CMC forms an adduct with $\Psi$ residues in RNA after a series of chemical treatments. The $\mathrm{CMC}-\Psi$ adduct can be detected by primer extension methods that result in a reverse transcriptase (RT) stop (Bakin and Ofengand 1993) and/or occasional RT readthrough that leaves behind a mutation signature in the sequencing reads (Lei and $\mathrm{Y}_{i}$ 2017; Zhou et al. 2018). The RT-stop method is the most commonly used approach. In either case, the multiple chemical handling steps generate higher than desired background in the sequencing reaction, so that mapping at the mRNA/IncRNA transcriptome level has not been consistent among different studies (Li et al. 2016; Safra et al. 2017). Furthermore, transcriptome-wide mapping methods have not generated reliable information on the $\Psi$ modification fraction at individual sites which is a biological variable in the response to cellular conditions.

Although candidate $\Psi$ sites in abundant rRNA or snRNA can be validated by primer extension and denaturing gel analysis or thin-layer chromatography (Zhao and $\mathrm{Yu}$ 2004), validation of $\Psi$ sites in low abundance mRNA/ IncRNA has been challenging. In principle, a SCARLETbased method can be used to validate and quantify a target $\Psi$ site in an mRNA (Liu et al. 2013), but this method requires radioactivity and requires a very large amount of input sample. Yi and colleagues developed a qPCR-based method for locus-specific detection of $\Psi$ (Lei and Yi 2017). This method relies on induced mutation/deletion in cDNA synthesis by the Superscript II RT; the resulting mutation/ deletion PCR products generate distinct melting curves after RT-PCR. Although this method is radiolabel free and useful in identifying $\Psi$ modification in mRNA, it cannot readily obtain quantitative information of $\Psi$ fraction at individual sites.

Here we develop an RT-PCR- and gel electrophoresisbased method that validates and quantifies $\Psi$ sites in mRNA/IncRNA at single-base resolution. Our method, termed CMC-RT and Ligation Assisted PCR analysis of $\Psi$ modification (CLAP), still relies on the initial generation of the CMC- $\Psi$ adduct at a target site and the RT stop it induces, but the RT stop product is selectively ligated to an oligonucleotide that subsequent PCR generates two different-sized products corresponding to the $\Psi$ modified and unmodified target RNA in the same sample using a single set of PCR primers. This uniform amplification of cDNAs derived from $\Psi$ modified and unmodified RNA produces quantitative information for individual $\Psi$ sites. We first show that CLAP is quantitative in determining $\Psi$ modification using an RNA standard and applying it to several rRNA $\Psi$ sites. We then apply CLAP to four target mRNAs and one target IncRNA $\Psi$ site previously identified by high-throughput sequencing. We validate the presence of $\Psi$ modification and obtain quantitative information about these mRNA/IncRNA sites in three human cell lines, thus demonstrating the utility of the method for quantitative investigations.

\section{RESULTS AND DISCUSSION}

\section{$\Psi$ in an RNA standard and rRNA}

The unique feature of the $\mathrm{CMC}$ reaction with U-like and G-like residues has been known since the 1970s and was first applied to identify $\Psi$ in rRNA and tRNA in 1993 by primer extension (Ho and Gilham 1971; Bakin and Ofengand 1993). $C M C$ can react with $U, G$, and $\Psi$ residues to form N3-CMC and N1-CMC adducts. All except the N3-CMC- $\Psi$ adducts are readily removed under alkaline conditions. In primer extension, the bulky N3-CMC group of $\Psi$ stops the reverse transcriptase one nucleotide $3^{\prime}$ to the $\Psi$ residue. This classical method has been adapted to map $\Psi$ sites in the transcriptome at hundreds or even thousands of sites (Carlile et al. 2014; Lovejoy et al. 2014; Schwartz et al. 2014; Li et al. 2015). The difficulty in using this method for low abundance mRNA transcripts is that sequencing reads that appear to be RT stops in the CMC-treated samples can be derived from multiple sources, which increases the noise for calling a $\Psi$ site. Thus, quantitative assessment of $\Psi$ fraction has not been reliable.

We developed a scheme to apply the CMC-based method for $\Psi$ analysis, but with the goal of validating $\Psi$ identification and at the same time quantifying the $\Psi$ modification level at a target site (Fig. 1A). We reasoned that the RT stop product derived from a target CMC-treated $\Psi$ site can be selectively amplified by ligating a DNA oligo guided by a complementary DNA splint to introduce the second PCR primer binding site. A crucial feature of our method is to make the second PCR primer binding site identical to a downstream region in the contiguous cDNA derived from the unmodified transcript encompassing the upstream RNA region to the target $\Psi$ site so that a single set of PCR primers can be used to amplify both the RT-stopped and contiguous cDNA products simultaneously. Our design allows for the PCR products to have different lengths, a short one corresponding to the $\Psi$ modified transcript and a 30 bp longer product corresponding to the unmodified transcript. The application of a single set of PCR primers provides the uniformity needed to quantify both short and long PCR products in the same reaction and in the same lane of a native gel. In contrast, conventional PCR methods involve two primer sets for RT-stop quantitation and use a subtractive strategy from two different PCR reactions, which increases a 

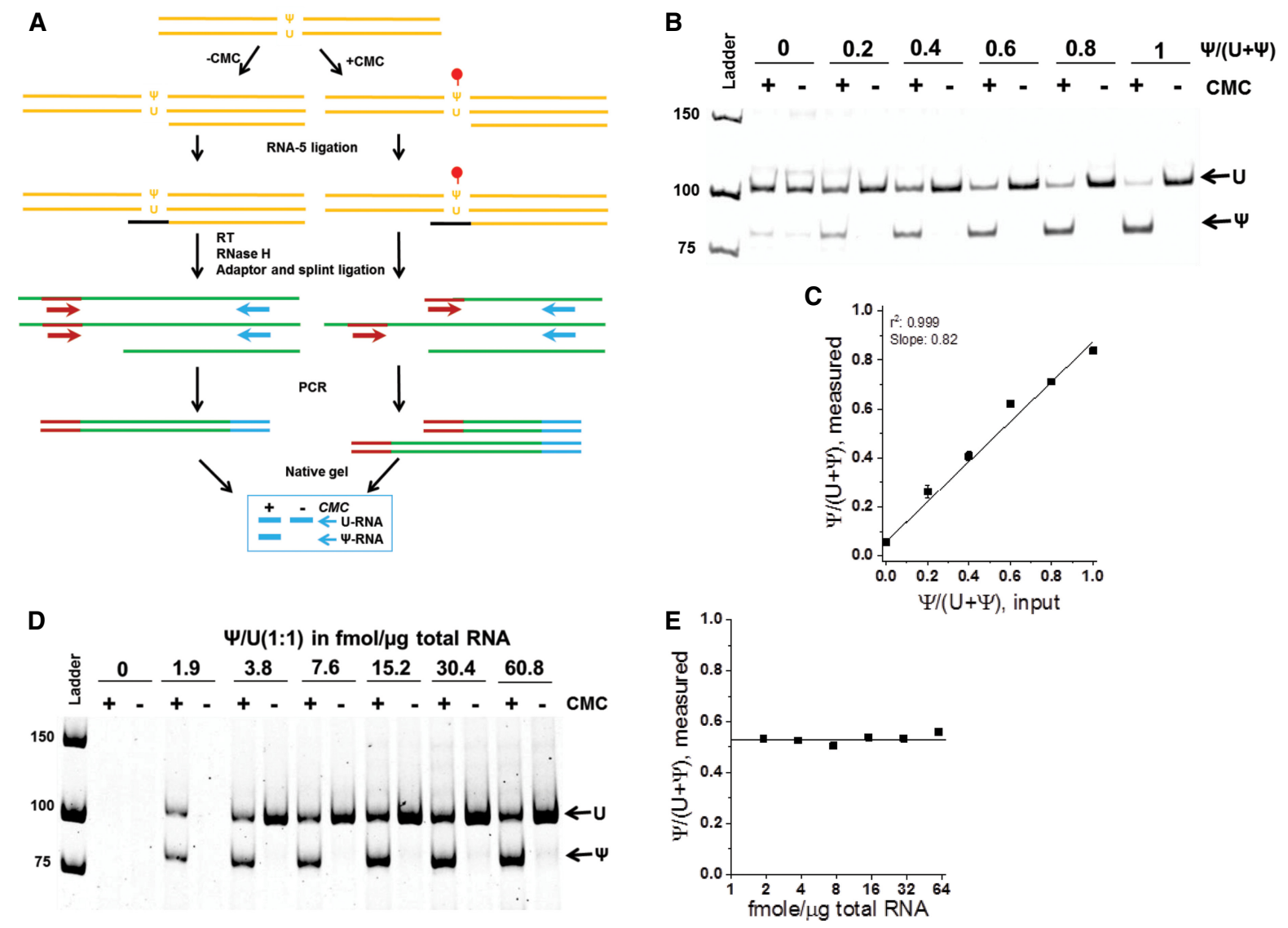

FIGURE 1. Schematics of the CLAP method and testing with U/ $\Psi$-containing RNA standards. (A) Schematics. RNA-5 is a $5 \mathrm{mer}$ RNA oligo used to block the randomly cleaved RNA during the CMC treatment. RNA is shown as an orange line, RNA-5 as black line, cDNA as a green line, and the ligated primer binding site in $\Psi+C M C$ as the red line at the end, with the same primer binding site in contiguous cDNA indicated as an embedded red line. PCR primers are represented by red and blue arrows. (B) Native PAGE showing two PCR bands derived from the U-and $\Psi$-containing RNA standard after the CLAP procedure. All samples contained $30 \mathrm{fmole}$ of 100mer RNA standard at indicated $\Psi$ fractions spiked into $1 \mu \mathrm{g}$ HEK293T total RNA. (C) Quantification of the result from panel B. The measured $\Psi$ fraction is calculated by subtracting the fraction of the short product band

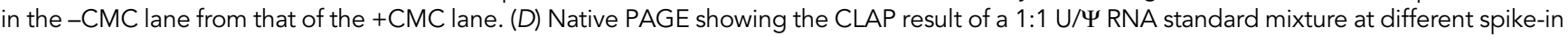
amounts added to $1 \mu \mathrm{g}$ HEK293T total RNA. (E) Quantification of the result from panel D.

nonuniform bias in the PCR reaction (Vandenbroucke et al. 2001). Although multiplex PCR can also be used to detect different CDNA products, the need to use different PCR primer pairs may also impose a PCR amplification bias, and the ratio of the PCR products cannot be visualized in a single lane (Singh et al. 2000). We termed our method CLAP which combines RT stops by $C M C-\Psi$, splint ligation, single-set primer PCR, and single lane visualization.

We first used a 100mer RNA standard to demonstrate the feasibility and the quantitative nature of the method (Fig. 1B). We mixed the fully $\Psi$-modified or unmodified 100 mers at defined ratios and spiked the mixture into the HEK293T total RNA to mimic the subsequent analysis of mRNA transcripts. We started with an optimized CMC reaction with $\Psi$ (Supplemental Fig. S1; Zhou et al. 2018) to obtain a nearly stoichiometric level of $C M C-\Psi$ adduct. $\mathrm{CMC}$ procedures rely on harsh conditions and produce a higher than desired level of RNA fragmentation.
The specific RNA cleavage product $3^{\prime}$ to the target $\Psi$ site would have produced the same RT product, thus increasing the background noise. To reduce this background, we first ligated a 5mer blocking RNA oligo to the free $5^{\prime}$ end of RNA cleavage products after the CMC treatment before carrying out the RT reaction (the RNA-5 ligation step in Fig. 1A). By optimizing the ligation conditions, we were able to reduce the non- $\Psi$ derived, short PCR product by at least fourfold (Supplemental Fig. S2). We performed RT reactions using the avian myoblastoma virus (AMV) reverse transcriptase, which is known to stop most frequently at $\Psi$-CMC adducts. In the CMC-treated sample, RT reaction would generate two cDNA products: a short one from the RT stop one nucleotide $3^{\prime}$ to the $\Psi$ site and a long product from contiguous CDNA synthesis of the unmodified RNA. Guided by a complementary DNA oligo splint, we ligated the RT-stop cDNA product to a DNA oligonucleotide containing the identical forward 
PCR primer binding site $>30$ bp away from the $\Psi$ site. Finally, we carried out PCR using just one set of forward and reverse primers to generate two PCR products corresponding to the $\Psi$-modified and unmodified RNA transcript. Analysis of the PCR products by native gel electrophoresis enabled the determination of $\Psi$ modification fraction. Using $\sim 30$ fmole of the 100mer RNA standard (1 ng) spiked into one microgram of total RNA, we found that the CLAP method can quantitatively assess the input $\Psi$ fraction (Fig. 1B,C). We also estimate from the calibration curve (Fig. 1C) that a $\Psi$ site modified at $\sim 5 \%$ level should be detectable using a twofold threshold above the background. To test the sensitivity of the CLAP method, we added a 1:1 mixture of $\Psi / U$-RNA standard to HEK293T total RNA at different concentrations. CLAP was able to precisely quantify the $\Psi$ fraction at a $\sim 1.9$ fmol level in one microgram of total RNA $(\sim 60 \mathrm{pg} / \mathrm{\mu g}$; Fig. 1D,E). Using an estimate of total poly(A) ${ }^{+}$RNA constituting $\sim 3 \%$ of total RNA, this level corresponds to $\sim 0.2 \%$ of total mRNA. In principle, CLAP should be able to analyze mRNA transcripts at even lower abundance upon increasing the PCR cycle number and additional optimization of PCR conditions.

To further validate the CLAP method, we examined three rRNA $\Psi$ sites that can be independently tested by visualizing the CMC- $\Psi$ derived RT stop products without amplification (Fig. 2). We chose one $\Psi$ site ( $\Psi 822)$ in $18 \mathrm{~S}$ rRNA and two $\Psi$ sites ( $\Psi 3749$ and $\Psi 4412$ ) in 28 S rRNA (Piekna-Przybylska et al. 2008; Taoka et al. 2018). Applying primer extension after $\mathrm{CMC}$ treatment, we found

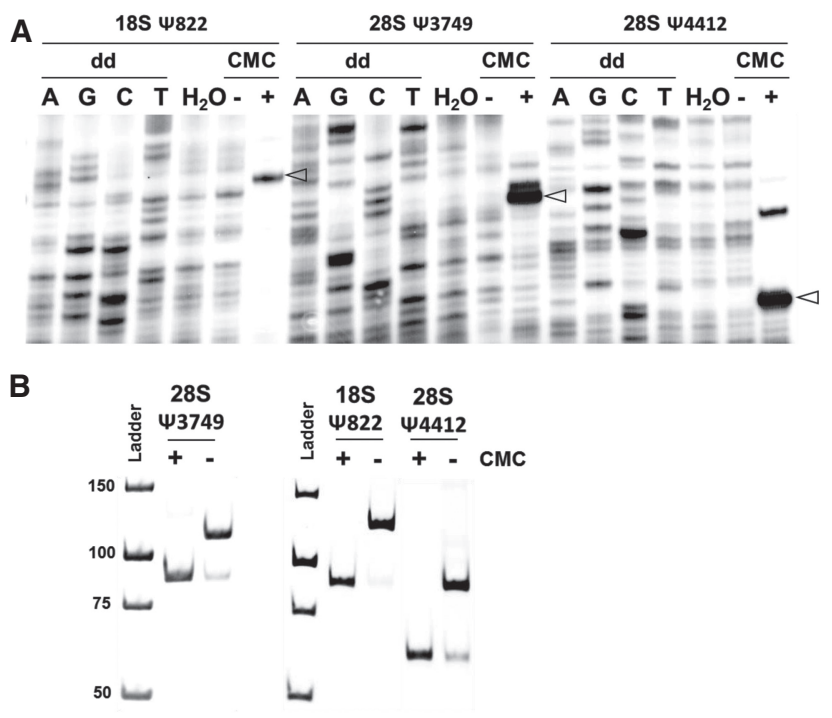

FIGURE 2. Quantification of $\Psi$ levels in rRNA. (A) Primer extension of the 18S $\Psi 822,28 \mathrm{~S} \Psi 3749$, and 28S $\Psi 4412$ sites. The RT stops are marked by a triangle. The estimated $\Psi$ modification levels are $74 \%$ for $\Psi 3749,84 \%$ for $\Psi 822$, and $66 \%$ for $\Psi 4412$. (B) CLAP result for the same three rRNA $\Psi$ sites. The estimated $\Psi$ modification levels are $74 \pm 3 \%$ for $\Psi 3749,83 \pm 1 \%$ for $\Psi 822$, and $71 \pm 1 \%$ for $\Psi 4412$. the $\Psi$ levels to be $84 \%$ for $18 \mathrm{~S} \Psi 822,74 \%$ for $28 \mathrm{~S} \Psi 3749$, and $66 \%$ for $28 \mathrm{~S} \Psi 4412$ (Fig. 2A). Applying the CLAP method, we determined the $\Psi$ levels to be $83 \%$ for $18 \mathrm{~S}$ $\Psi 822,74 \%$ for $28 \mathrm{~S} \Psi 3749$, and $71 \%$ for $28 \mathrm{~S} \Psi 4412$ (Fig. 2B). This agreement between the primer extension and CLAP methods supports the feasibility of using CLAP for quantitative analysis of $\Psi$ modifications. The modification fraction of the same three sites detected by mass spectrometry using TK6 rRNA were all $>99 \%$ (Taoka et al. 2018). This result suggests that the CLAP method is semiquantitative to measure the absolute $\Psi$ modification fraction and may underestimate the $\Psi$ fraction by up to 1.4-fold, likely due to either incomplete CMC- $\Psi$ adduct formation and/or a small amount of CMC- $\Psi$ reversal in the $\mathrm{CMC}$ procedure.

\section{$\Psi$ in mRNA and IncRNA}

Next, we examined the $\Psi$ status of two $\Psi$ sites in the abundant eEF1A1 mRNA and one $\Psi$ site in MALAT1 IncRNA. eEF1A1 is an isoform of the $\alpha$ subunit of the elongation factor-1 complexand plays an essential role in translation by delivering aminoacyl-tRNA to the ribosome. This mRNA has been frequently used as a reference for QPCR studies (Gentile et al. 2016; Mughal et al. 2018). MALAT1 is a metastasis-promoting IncRNA and plays a role in alternative splicing, nuclear organization, epigenetic modulation of gene expression, synapse formation, and myogenesis (Zhang et al. 2017). Previous $\Psi$ sequencing (CeU-seq, Li et al. 2015) identified two $\Psi$ sites in eEF1A1 ( $\Psi 519$ and $\Psi 875)$ and one $\Psi$ site in MALAT1 ( $\Psi 5590)$. These sites have been validated by a QPCR-based $\Psi$ detection method (Lei and Yi 2017). Applying the CLAP method, we determined the modification level of eEF1A1 $\Psi 519$ at $31 \pm 2 \%$, eEF1A1 $\Psi 875$ at $56 \pm 3 \%$, and MALAT1 $\Psi 5590$ at $84 \pm 5 \%$ in HEK293T cells (Fig. 3A). The nearly complete pseudouridylation of the MALAT1 site is consistent with the high modification level ( 75\%) estimated by a qPCR-based method (Lei and Yi 2017). We also examined these $\Psi$ sites in HeLa and MCF7 cell lines (Fig. 3B). eEF1A1 4875 and MALAT1 $\Psi 5590$ had similar $\Psi$ modification levels in all three cell lines; in contrast, eEF1A1 $\Psi 875$ levels ranged from $56 \pm 3 \%$ in HEK293T to $35 \pm 2 \%$ in MCF7.

To investigate the sensitivity of the CLAP method we chose two $\Psi$ sites in low abundance mRNAs, hypoxanthine phosphoribosyltransferase 1 (HPRT1), and proteasome activator subunit 2 (PSME2) identified by CeU-seq (Li et al. 2015; Lei and Yi 2017). Both mRNAs are present at $<1 \%$ the abundance of the eEF1A1 mRNA according to mRNA-seq analysis in HEK293T cells (Liu et al. 2017). We used $1 \mu \mathrm{g}$ HEK293T total RNA to successfully measure the $\Psi$ status of HPRT1 $\Psi 733$ and PSME2 $\Psi 616$. Applying the CLAP method, we determined that the modification level of HPRT1 $\Psi 733$ was $51 \pm 1 \%$ and of PSME2 $\Psi 616$ $62 \pm 5 \%$ (Fig. 4A). To validate the accuracy and sensitivity 

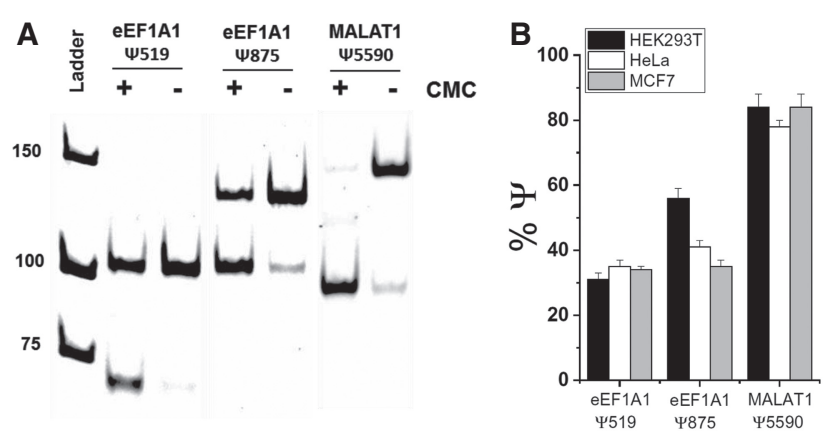

FIGURE 3. CLAP analysis of $\Psi$ in high abundance $m R N A$ and IncRNA transcripts. (A) CLAP examination of eEF1A1 $\Psi 519$, eEF1A1 $\Psi 875$, and MALAT1 45590 sites using $1 \mu \mathrm{g}$ HEK293T total RNA. (B) $\Psi$ modification levels in three cell lines, three biological replicates for each site.

of measuring $\Psi$ status in low abundance mRNA in the context of total RNA by CLAP, we also used 50 ng poly(A)selected RNA as input for the CLAP procedure (Fig. 4B). We found similar levels for HPRT1 4733 [51\% in total RNA and $46 \%$ in poly(A)-selected RNA] and a 1.4-fold higher level for PSME2 $\Psi 616$ [62\% in total RNA and $86 \%$ in poly (A)-selected RNA]. Both sites showed similar modification levels among the three cell lines examined (Fig. 4C).

To assess the functional relevance of these $5 \Psi$ sites, we performed phylogenetic analysis among the vertebrate lineage (Supplemental Fig. S3) using Jalview (Waterhouse et al. 2009). The four mRNA $\Psi$-containing regions are conserved across vertebrates, whereas the $\Psi 5590$-containing region is only present in the MALAT1 RNA from primates. All four mRNA sites are in the coding regions and part of a Val codon. The eEF1A1 $\Psi 519$ site is in the third codon position (GUY); this uridine is sometimes changed to $C_{\text {, }}$ which still maintains the amino acid identity of the codon. eEF1A1 $\Psi 875$, HPRT1 $\Psi 733$, and PSME2 $\Psi 616$ sites

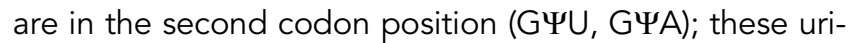
dines are unchanged in all vertebrates. The conserved $\Psi$
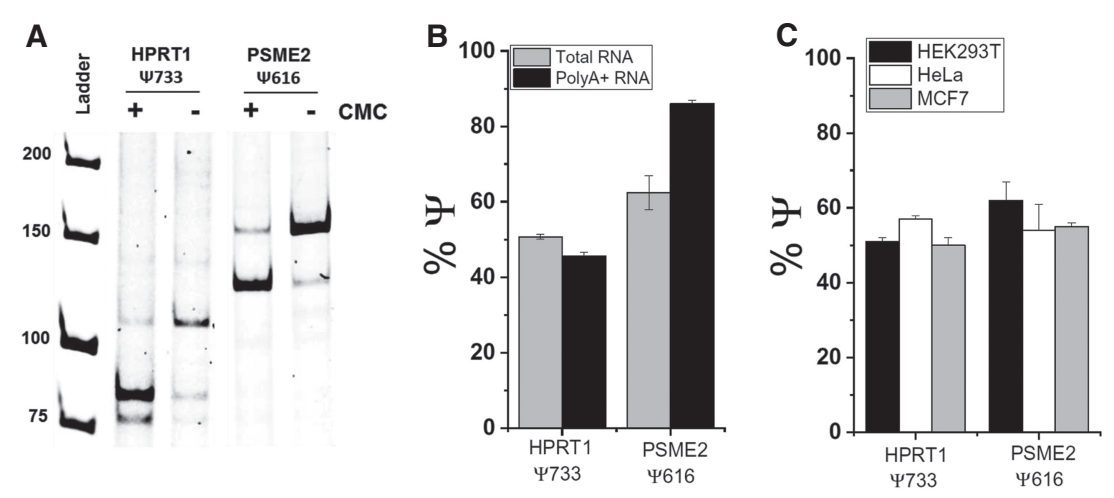

FIGURE 4. CLAP analysis of $\Psi$ in low abundance mRNA transcripts. (A) CLAP results for HPRT1 4733 and PSME2 $\Psi 616$ using $1 \mu \mathrm{g}$ of HEK293T total RNA as input. (B) CLAP quantitation of HPRT1 4733 and PSME2 4616 using HEK293T total RNA (1 $\mu \mathrm{g}$ input) or poly(A) ${ }^{+}$RNA (50 ng input). (C) $\Psi$ modification levels in three cell lines, three biological replicates for each site. modification in the second codon position may be useful for decoding these Val codons.

In summary, we developed a sensitive and quantitative RT-PCR method for site-specific analysis of $\Psi$ modification. Our method can validate candidate $\Psi$ sites in target mRNA and IncRNA using total RNA and directly visualize the modification levels. Since CLAP makes use of RT stops, in principle it can be applied to site-specific detection and quantitation of other RNA modifications that induce RT stops during cDNA synthesis. These include the Watson-Crick face RNA methylations of $N^{1}$-methyladenosine $\left(m^{1} A\right), N^{3}$-methylcytidine $\left(m^{3} \mathrm{C}\right), N^{1}$-methylguanosine $\left(m^{1} \mathrm{G}\right), N^{2}, N^{2}$-dimethylguanosine $\left(m^{2}{ }_{2} G\right)$, and $N^{3}$-methyluridine $\left(m^{3} U\right) \cdot m^{1} A$ has already been shown to be present in mammalian mRNAs, but its modification levels at target sites have not been investigated (Dominissini et al. 2016; Li et al. 2017). A potential limitation of the CLAP method is for closely spaced two or more $\Psi$ sites in the same RNA, it can only accurately assess the $3^{\prime}$ most $\Psi$ site.

Among the mRNA/IncRNA target sites we analyze here, $\Psi$ level ranges from $30 \%$ to $85 \%$, which is compatible to the more abundant $\mathrm{m}^{6} \mathrm{~A}$ modification in mRNA/IncRNA. Quantitative measurement of the modification level is an important biological feature in the epitranscriptome that has not received much attention. The quantitative nature of our CLAP method in the determination of $\Psi$ status in low abundance mRNAs should enable the investigation of cell type- and cell state-dependent variations in $\Psi$ levels.

\section{MATERIALS AND METHODS}

\section{Cell culture and RNA extraction}

HEK293T, HeLa, and MCF7 cells were cultured under standard conditions. Briefly, HEK293T and HeLa cells were grown in Hyclone DMEM medium (GE Healthcare Life Sciences, SH30022.01) with 10\% FBS and 1\% Pen-Strep (PenicillinStreptomycin) to $80 \%$ confluency. MCF7 cells were grown in EMEM medium (ATCC, 30-2003) with 10\% FBS, 1\% PenStrep, $0.01 \mathrm{mg} / \mathrm{mL}$ bovine insulin (SigmaAldrich, 10516), and $10 \mathrm{nM} \beta$-estradiol (Sigma-Aldrich, E2758) to 80\% confluency. Total RNA was extracted using TRIzol reagent (ThermoFisher, 15596026) following the manufacturer's protocol. Poly $(A)^{+}$ RNA was enriched using the PolyATtract mRNA Isolation System (Promega, Z5310) following the manufacturer's instructions.

\section{In vitro transcription of U- or $\Psi$-containing control oligos}

The 100-nt U- or $\Psi$-containing RNA standard was in vitro transcribed using T7 
RNA polymerase. In vitro transcription took place in $1 \times$ RNA polymerase buffer; $14 \mathrm{mM} \mathrm{MgCl}_{2} ; 5 \mathrm{mM}$ DTT; $4 \mathrm{mM}$ each ATP, GTP, CTP; 4 mM UTP or ITP (TriLink BioTechnologies, N-1019); 10 U/ $\mu \mathrm{L}$ T7 RNA polymerase (NEB, M0251L); and $85 \mathrm{nM}$ dsDNA template. The whole mixture was incubated at $37^{\circ} \mathrm{C}$ for $2.5 \mathrm{~h}$. Then $1 / 10$ th volume of $3 \mathrm{M} \mathrm{NaOAc} / \mathrm{HOAc}(\mathrm{pH} 5.2)$ and $3 \times$ volume of $100 \%$ ethanol were added to the mixture to precipitate the RNA oligos. The precipitated RNA oligos were purified using $10 \%$ denaturing gels containing $7 \mathrm{M}$ urea.

The sequence of the RNA standard is as follows:

\section{5'-GgGAGGCGAGAACACACCACAACGAAAACGAGCAAAA} CCCGG( $(\Psi / U) A C G C A A C A C A A A A G C G A A C A A C G C G A A A A A$ GGACACCGAAGCGGAAGCAAAGACAAC-3'

\section{CMC treatment of RNA}

Total RNA or poly(A) ${ }^{+}$RNA was CMC [N-cyclohexyl-N'-(2-morpholinoethyl)carbodiimide] labeled as previously described (Zhou et al., 2018). A major change in this work is the increased CMC reaction time $(\sim 16 \mathrm{~h})$ at lower temperature $\left(30^{\circ} \mathrm{C}\right)$ to ensure nearly complete conversion of $\Psi$ to $\Psi-C M C$ while minimizing RNA degradation. Briefly, $10 \mu \mathrm{g}$ total RNA or poly(A) ${ }^{+}$RNA in $12 \mu \mathrm{L}$ water was mixed with $24 \mu \mathrm{L}$ of $1 \times$ TEU buffer consisting of $50 \mathrm{mM}$ Tris- $\mathrm{HCl}(\mathrm{pH}$ 8.3), 4 mM EDTA, $7 \mathrm{M}$ urea, and $4 \mu \mathrm{L}$ of $1 \mathrm{M}$ freshly prepared $\mathrm{CMC}$ in TEU buffer (+CMC) or just $4 \mu \mathrm{L}$ TEU buffer $(-C M C)$ for a final condition of $0.7 \times$ TEU buffer in $40 \mu \mathrm{L}$. The $\mathrm{CMC}$ reaction was carried out at $30^{\circ} \mathrm{C}$ for $16 \mathrm{~h}$. To remove excess $\mathrm{CMC}$, the following reagents were added to the reaction mixture: $160 \mu \mathrm{L}$ of $50 \mathrm{mM} \mathrm{KOAc}(\mathrm{pH}$ 7), $200 \mathrm{mM} \mathrm{KCl} ; 3 \mu \mathrm{L}$ of $5 \mu \mathrm{g} / \mu \mathrm{L}$ glycogen; and then $550 \mu \mathrm{L}$ of ethanol. The mixture was incubated at $-80^{\circ} \mathrm{C}$ for $>2 \mathrm{~h}$, then centrifuged at $15 \mathrm{krpm}$ in a micro-centrifuge for $30 \mathrm{~min}$. After removing the supernatant, the pellet was mixed with $500 \mu \mathrm{L}$ of $75 \%$ ethanol and then kept at $-80^{\circ} \mathrm{C}$ for at least $2 \mathrm{~h}$ and centrifuged once more. The washing and precipitation steps were repeated one more time. To reverse the CMC-U/CMC-G adducts, the RNA pellet was mixed with $40 \mu \mathrm{L}$ of $50 \mathrm{mM} \mathrm{Na}_{2} \mathrm{CO}_{3}, 2 \mathrm{mM} \mathrm{EDTA}$ ( $\mathrm{pH}$ 10.4), and incubated at $37^{\circ} \mathrm{C}$ for $6 \mathrm{~h}$. The reaction mixture was then mixed with $160 \mu \mathrm{L}$ of $50 \mathrm{mM} \mathrm{KOAc}$ (pH 7), $200 \mathrm{mM} \mathrm{KCl}$, followed by ethanol precipitation. The RNA recovery yield for this protocol was $>65 \%$.

\section{RNA 5' phosphorylation and RNA-5 blocking oligo ligation}

To reduce the signal derived from RNA fragmentation during the CMC reaction, \pm CMC-treated RNA in $6.5 \mu \mathrm{L} \mathrm{H} \mathrm{H}_{2} \mathrm{O}$ was mixed with $0.5 \mu \mathrm{L}$ RNase inhibitor (NEB, M0307L), $1 \mu \mathrm{L}$ of $10 \times \mathrm{T} 4 \mathrm{PNK}$ reaction buffer $\mathrm{A}, 1 \mu \mathrm{L}$ of $1 \mathrm{mM}$ ATP, $1 \mu \mathrm{L}$ of T4 Polynucleotide kinase (PNK), and then incubated at $37^{\circ} \mathrm{C}$ for $30 \mathrm{~min}$. To ligate the RNA-5 oligo (/5AmMC6/rArCrCrCrA; Integrated DNA Technologies), $1 \mu \mathrm{L}$ of $10 \times$ T4 RNA Ligase Reaction Buffer, $1 \mu \mathrm{L}$ of $100 \mu \mathrm{M}$ RNA-5 oligo, $1 \mu \mathrm{L}$ of $1 \mathrm{mM}$ ATP, $1 \mu \mathrm{L}$ of RNase inhibitor, $3 \mu \mathrm{L}$ of DMSO, $2 \mu \mathrm{L}$ of $\mathrm{H}_{2} \mathrm{O}$, and $1 \mu \mathrm{L}$ of T4 RNA ligase I (NEB, M0437M) were added to this mixture and incubated at $16^{\circ} \mathrm{C}$ for $16 \mathrm{~h}$. The reaction was terminated upon the addition of $1.2 \mu \mathrm{L}$ of $200 \mathrm{mM}$ EDTA.

\section{Reverse transcription and splint ligation}

Reverse transcription was carried out using $3 \mu \mathrm{L}$ of the above ligation mixture ( $1 \mu \mathrm{g}$ RNA) using AMV reverse transcriptase (NEB,
$\mathrm{M} 0277 \mathrm{~L})$ and target-specific primers. To anneal the primer, $1 \mu \mathrm{L}$ of $10 \times$ annealing buffer ( $250 \mathrm{mM}$ Tris- $\mathrm{HCl}$ [pH 7.4], $480 \mathrm{mM}$ $\mathrm{KCl}$ ) and $1 \mu \mathrm{L}$ of $0.5 \mu \mathrm{M}$ target-specific RT primer were added, and the mixture was incubated at $93^{\circ} \mathrm{C}$ for $2 \mathrm{~min}$. To start the $\mathrm{RT}$ reaction, $5 \mu \mathrm{L}$ of $2 \times \mathrm{AMV} \mathrm{RT}$ reaction mixture was added for a final condition of $0.6 \mathrm{U} / \mu \mathrm{L}$ AMV RT, $1 \times$ AMV RT buffer, and $0.5 \mathrm{mM}$ of each dNTP. The RT reaction proceeded at $42^{\circ} \mathrm{C}$ for $1 \mathrm{~h}$. After incubation at $85^{\circ} \mathrm{C}$ for $5 \mathrm{~min}$ to inactivate RT, $1 \mu \mathrm{L}$ of $5 \mathrm{U} / \mu \mathrm{L}$ RNase $\mathrm{H}$ (NEB, M0297L) was added and the mixture incubated at $37^{\circ} \mathrm{C}$ for 20 min to digest the RNA. RNase $\mathrm{H}$ was inactivated by heating the mixture at $85^{\circ} \mathrm{C}$ for $5 \mathrm{~min}$.

To anneal the adaptor, $1 \mu \mathrm{L}$ of the adaptor/splint oligos mixture (1.5 $\mu \mathrm{M}$ each) was added to the above RT mixture, followed by incubation at $75^{\circ} \mathrm{C}$ for $3 \mathrm{~min}$. To ligate the adaptor, $4 \mu \mathrm{L}$ of $4 \times$ ligation mixture was added for a final concentration of $10 \mathrm{U} / \mu \mathrm{L}$ of T4 DNA ligase (NEB, M0202L), 1× T4 DNA ligase reaction buffer, and $12.5 \%$ DMSO. The ligation proceeded at $16^{\circ} \mathrm{C}$ for $16 \mathrm{~h}$. DNA ligase was inactivated by heating the mixture at $65^{\circ} \mathrm{C}$ for $10 \mathrm{~min}$.

\section{PCR amplification and gel electrophoresis}

To perform PCR, $2 \mu \mathrm{L}$ of the above ligation mixture was mixed with various components for a final condition of $1 \times 05$ reaction buffer, $1 \times$ Q5 high GC enhancer, $200 \mu \mathrm{M}$ of each dNTP, $0.5 \mu \mathrm{M}$ forward and reverse primers, and $0.02 \mathrm{U} / \mu \mathrm{L}$ Q5 high-fidelity DNA polymerase (NEB, M0491L); the final PCR reaction volume was $35 \mu \mathrm{L}$. PCR was done for high abundance eEF1A1 mRNA and MALAT1 RNA sites at 15 cycles and for low abundance PSME2 and HPRT1 sites 25-35 cycles.

Half of the PCR mixture $(17.5 \mu \mathrm{L})$ was mixed with $3.5 \mu \mathrm{L}$ of $6 \times$ TriTrack DNA Loading Dye (ThermoFisher, R1161). The entire mixture was loaded on a prerun $10 \%$ nondenaturing gel containing $1 \times$ TBE, together with low range DNA ladder (ThermoFisher, SM1193). The gel was stained with SYBR gold nucleic acid gel stain (ThermoFisher, S11494) for $10 \mathrm{~min}$. Product bands were visualized using the Bio-Rad ChemiDoc imaging system and the bands quantified using Image Lab.

\section{CLAP primer and oligonucleotide sequences}

PseudoU_Ctrl RT Primer: 5'-GTTGTCTTTGCTTCCGCTT CG-3'

PseudoU_Ctrl Adaptor: 5'-pCCATGGGTGTGTTCTCGCC TCCC-3'

PseudoU_Ctrl Splint: 5'-ACACCCATGGACGCAACACA/ 3SpC3/-3'

PseudoU_Ctrl Forward PCR Primer: 5'-GGGAGGCGA GAACACACC-3'

28S $\Psi 3749$ RT Primer: 5'-TCGTTCATCCATTCATGCG C-3'

28S 43749 Adaptor: 5'-pCCATGGCGCTTCATTGAATT TCTTCAC-3'

28S $\Psi 3749$ Splint: 5'-AGCGCCATGGCTTAAGGTAG/ $3 \mathrm{SpC} 3 /-3^{\prime}$

28S 43749 Forward PCR Primer: 5'-GTGAAGAAATTCAA TGAAGCGC-3' 
18S 4822 RT Primer: 5'-AACCGCGGTCCTATTCCATTA TT-3'

18S 4822 Adaptor: 5'-pCCATGGACACTCAGCTAAGA GCATCG-3'

18S $\Psi 822$ Splint: 5'-GTGTCCATGGTCAAAGCAGG/ $3 \mathrm{SpC} 3 /-3^{\prime}$

18S $\Psi 822$ Forward PCR Primer: 5'- CGATGCTCTTA GCTGAGTGTC-3'

28S 44412 RT Primer: 5'-TGCTTCACAATGATAGGAAGA GCC-3'

28S $\Psi 4412$ Adaptor: 5'-pCCATGCCGCCACAAGCCA GTTAT-3'

28S $\Psi 4412$ Splint: 5'-GGCGGCATGGCCTTCGATGT/ $3 \mathrm{SpC} 3 /-3^{\prime}$

28S 44412 Forward PCR Primer: 5'-ATAACTGGCTTG TGGCGG-3'

EEF1A1 4519 RT Primer: 5'-ATATCTCTTCTGGCTG TAGGGTG-3'

EEF1A1 $\Psi 519$ Adaptor: 5'-pCCATGGCCAGAAGGGC ATGCTCT-3'

EEF1A1 $\Psi 519$ Splint: 5'-CTGGCCATGGAACAAAATGG/ $3 \mathrm{SpC} 3 /-3^{\prime}$

EEF1A1 $\Psi 519$ Forward PCR Primer: 5'-AGAGCATG CCCTTCTGGC-3'

EEF1A1 4875 RT Primer: 5'-TGCATTTCGACAGATTTTAC TTCCG-3'

EEF1A1 $\Psi 875$ Adaptor: 5'-pCCATGTACCACCAATTTT GTAGACATCCTG-3'

EEF1A1 $\Psi 875$ Splint: 5'-TGGTACATGGTCTCAAACCC/ $3 \mathrm{SpC} 3 /-3^{\prime}$

EEF1A1 4875 Forward PCR Primer: 5'-CAGGATGTCTA CAAAATTGGTGGTA-3'

MALAT1 $\Psi 5590$ RT Primer: 5'-TAAAGATGCAAATG CCTCTGAGTGA-3'

MALAT1 $\Psi 5590$ Adaptor: 5'-pCCATGAGGAGAAAGTG CCATGGTTGATATT-3'

MALAT1 $\Psi 5590$ Splint: 5'-CTCCTCATGGAGGACTTGTT/ 3SpC3/-3'

MALAT1 $\Psi 5590$ Forward PCR Primer: 5'-AATATCAACCA TGGCACTTTCTCCT-3'

HPRT1 4733 RT Primer: 5'-GACACAAACATGATTCAAAT CCCTG-3'

HPRT1 4733 Adaptor: 5'-pCCATGAAAGTCTGGCTTATA TCCAACACTT-3'

HPRT1 $\Psi 733$ Splint: 5'-ACTTTCATGGAGGATATGCC/ $3 \mathrm{SpC} 3 /-3^{\prime}$

HPRT1 4733 Forward PCR Primer: 5'-AAGTGTTGGATA TAAGCCAGACTTT-3'

PSME2 4616 RT Primer: 5'-TATGATAAAGCTCAGCATAG AAGGC-3'

PSME2 $\Psi 616$ Adaptor: 5'-pCCATGCGTTCTGAGAAG TACTTGGAAATGG -3'

PSME2 $\Psi 616$ Splint: 5'-GAACGCATGGAATGGATTAC/ $3 \mathrm{SpC} 3 /-3^{\prime}$

PSME2 4616 Forward PCR Primer: 5'-CCATTTCCAAGTA CTTCTCAGAACG-3'

\section{SUPPLEMENTAL MATERIAL}

Supplemental material is available for this article.

\section{ACKNOWLEDGMENTS}

This work was supported by the National Institutes of Health $(\mathrm{NIH}$; RM1HG008935 to T.P.; F32GM126745 and 5T32HL007381 to M.J.E.).

Received May 24, 2019; accepted June 20, 2019.

\section{REFERENCES}

Bakin A, Ofengand J. 1993. Four newly located pseudouridylate residues in Escherichia coli $23 \mathrm{~S}$ ribosomal RNA are all at the peptidyltransferase center: analysis by the application of a new sequencing technique. Biochemistry 32: 9754-9762. doi:10.1021/ bi00088a030

Carlile TM, Rojas-Duran MF, Zinshteyn B, Shin H, Bartoli KM, Gilbert WV. 2014. Pseudouridine profiling reveals regulated mRNA pseudouridylation in yeast and human cells. Nature 515: 143-146. doi:10.1038/nature13802

Charette M, Gray MW. 2000. Pseudouridine in RNA: what, where, how, and why. IUBMB Life 49: 341-351. doi:10.1080/ 152165400410182

Delaunay S, Frye M. 2019. RNA modifications regulating cell fate in cancer. Nat Cell Biol 21: 552-559. doi:10.1038/s41556-0190319-0

Dominissini D, Nachtergaele S, Moshitch-Moshkovitz S, Peer E, Kol N, Ben-Haim MS, Dai Q, Di Segni A, Salmon-Divon M, Clark WC, et al. 2016. The dynamic $N^{1}$-methyladenosine methylome in eukaryotic messenger RNA. Nature 530: 441-446. doi:10.1038/ nature16998

Ge J, Yu YT. 2013. RNA pseudouridylation: new insights into an old modification. Trends Biochem Sci 38: 210-218. doi:10.1016/j .tibs.2013.01.002

Gentile AM, Lhamyani S, Coín-Aragüez L, Oliva-Olivera W, Zayed H, Vega-Rioja A, Monteseirin J, Romero-Zerbo SY, Tinahones FJ, Bermúdez-Silva FJ, et al. 2016. RPL13A and EEF1A1 are suitable reference genes for QPCR during adipocyte differentiation of vascular stromal cells from patients with different BMI and HOMA-IR. PLoS ONE 11: e0157002. doi:10.1371/journal.pone.0157002

Guzzi N, Cieśla M, Ngoc PCT, Lang S, Arora S, Dimitriou M, Pimková K, Sommarin MNE, Munita R, Lubas M, et al. 2018. Pseudouridylation of tRNA-derived fragments steers translational control in stem cells. Cell 173: 1204-1216.e26. doi:10.1016/j .cell.2018.03.008

Ho NW, Gilham PT. 1971. Reaction of pseudouridine and inosine with $N$-cyclohexyl- $N^{\prime}$ - $\beta$-(4-methylmorpholinium)ethylcarbodiimide. Biochemistry 10: 3651-3657. doi:10.1021/bi00796a003

Karijolich J, Yu YT. 2011. Converting nonsense codons into sense codons by targeted pseudouridylation. Nature 474: 395-398. doi: 10 $.1038 /$ nature 10165

Lei Z, Yi C. 2017. A radiolabeling-free, qPCR-based method for locusspecific pseudouridine detection. Angew Chem Int Ed Engl 56: 14878-14882. doi:10.1002/anie.201708276

Li X, Zhu P, Ma S, Song J, Bai J, Sun F, Yi C. 2015. Chemical pulldown reveals dynamic pseudouridylation of the mammalian transcriptome. Nat Chem Biol 11: 592-597. doi:10.1038/nchembio.1836

Li X, Ma S, Yi C. 2016. Pseudouridine: the fifth RNA nucleotide with renewed interests. Curr Opin Chem Biol 33: 108-116. doi:10 .1016/j.cbpa.2016.06.014 
Li X, Xiong X, Zhang M, Wang K, Chen Y, Zhou J, Mao Y, Lv J, Yi D, Chen $X W$, et al. 2017. Base-resolution mapping reveals distinct $\mathrm{m}^{1} \mathrm{~A}$ methylome in nuclear- and mitochondrial-encoded transcripts. Mol Cell 68: 993-1005.e9. doi:10.1016/j.molcel.2017.10 .019

Liu N, Parisien M, Dai Q, Zheng G, He C, Pan T. 2013. Probing $N^{6}$ methyladenosine RNA modification status at single nucleotide resolution in mRNA and long noncoding RNA. RNA 19: 1848-1856. doi:10.1261/rna.041178.113

Liu N, Zhou KI, Parisien M, Dai Q, Diatchenko L, Pan T. 2017. N' -methyladenosine alters RNA structure to regulate binding of a low-complexity protein. Nucleic Acids Res 45: 6051-6063. doi:10.1093/ nar/gkx141

Lovejoy AF, Riordan DP, Brown PO. 2014. Transcriptome-wide mapping of pseudouridines: pseudouridine synthases modify specific mRNAs in S. cerevisiae. PLoS ONE 9: e110799. doi:10.1371/jour nal.pone.0110799

Mughal BB, Leemans M, Spirhanzlova P, Demeneix B, Fini JB. 2018. Reference gene identification and validation for quantitative real-time PCR studies in developing Xenopus laevis. Sci Rep 8: 496. doi:10.1038/s41598-017-18684-1

Piekna-Przybylska D, Decatur WA, Fournier MJ. 2008. The 3D rRNA modification maps database: with interactive tools for ribosome analysis. Nucleic Acids Res 36: D178-D183. doi:10.1093/nar/gkm855

Rintala-Dempsey AC, Kothe U. 2017. Eukaryotic stand-alone pseudouridine synthases-RNA modifying enzymes and emerging regulators of gene expression? RNA Biol 14: 1185-1196. doi:10 $.1080 / 15476286.2016 .1276150$

Safra M, Nir R, Farouq D, Vainberg Slutskin I, Schwartz S. 2017. TRUB1 is the predominant pseudouridine synthase acting on mammalian mRNA via a predictable and conserved code. Genome Res 27: 393-406. doi:10.1101/gr.207613.116

Schwartz S, Bernstein DA, Mumbach MR, Jovanovic M, Herbst RH, León-Ricardo BX, Engreitz JM, Guttman M, Satija R, Lander ES, et al. 2014. Transcriptome-wide mapping reveals widespread dynamic-regulated pseudouridylation of ncRNA and mRNA. Cell 159: 148-162. doi:10.1016/j.cell.2014.08.028

Singh RP, Nie X, Singh M. 2000. Duplex RT-PCR: reagent concentrations at reverse transcription stage affect the PCR performance. $J$ Virol Methods 86: 121-129. doi:10.1016/S0166-0934(00)00138-5

Taoka M, Nobe Y, Yamaki Y, Sato K, Ishikawa H, Izumikawa K, Yamauchi Y, Hirota K, Nakayama H, Takahashi N, et al. 2018. Landscape of the complete RNA chemical modifications in the human 80S ribosome. Nucleic Acids Res 46: 9289-9298. doi:10 $.1093 /$ nar/gky811

Vandenbroucke II, Vandesompele J, Paepe AD, Messiaen L. 2001. Quantification of splice variants using real-time PCR. Nucleic Acids Res 29: E68. doi:10.1093/nar/29.13.e68

Waterhouse AM, Procter JB, Martin DM, Clamp M, Barton GJ. 2009. Jalview Version 2-a multiple sequence alignment editor and analysis workbench. Bioinformatics 25: 1189-1191. doi:10.1093/ bioinformatics/btp033

Wu G, Xiao M, Yang C, Yu YT. 2011. U2 snRNA is inducibly pseudouridylated at novel sites by Pus7p and snR81 RNP. EMBO J 30: 7989. doi:10.1038/emboj.2010.316

Wu G, Adachi H, Ge J, Stephenson D, Query CC, Yu YT. 2016. Pseudouridines in U2 snRNA stimulate the ATPase activity of Prp5 during spliceosome assembly. EMBO J 35: 654-667. doi:10.15252/embj.201593113

Zhang X, Hamblin MH, Yin KJ. 2017. The long noncoding RNA Malat1: its physiological and pathophysiological functions. RNA Biol 14: 1705-1714. doi:10.1080/15476286.2017.1358347

Zhao X, Yu YT. 2004. Detection and quantitation of RNA base modifications. RNA 10: 996-1002. doi:10.1261/rna.7110804

Zhou KI, Clark WC, Pan DW, Eckwahl MJ, Dai Q, Pan T. 2018. Pseudouridines have context-dependent mutation and stop rates in high-throughput sequencing. RNA Biol 15: 892-900. doi:10 $.1080 / 15476286.2018 .1462654$ 

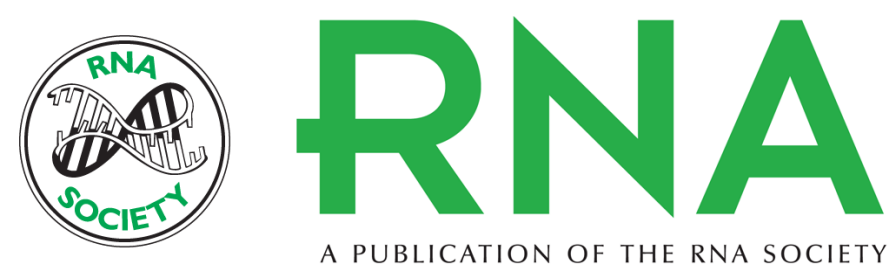

A PUBLICATION OF THE RNA SOCIETY

\section{Sensitive and quantitative probing of pseudouridine modification in mRNA and long noncoding RNA}

Wen Zhang, Matthew J. Eckwahl, Katherine I. Zhou, et al.

RNA 2019 25: 1218-1225 originally published online June 21, 2019

Access the most recent version at doi:10.1261/rna.072124.119

\section{Supplemental http://rnajournal.cshlp.org/content/suppl/2019/06/21/rna.072124.119.DC1 Material}

References This article cites 31 articles, 3 of which can be accessed free at: http://rnajournal.cshlp.org/content/25/9/1218.full.html\#ref-list-1

Creative This article is distributed exclusively by the RNA Society for the first 12 months after the Commons License full-issue publication date (see http://rnajournal.cshlp.org/site/misc/terms.xhtml). After 12 months, it is available under a Creative Commons License (Attribution-NonCommercial 4.0 International), as described at http://creativecommons.org/licenses/by-nc/4.0/.
Email Alerting Receive free email alerts when new articles cite this article - sign up in the box at the Service top right corner of the article or click here.

\section{III!" PI Providing Precise Solutions for your research.}

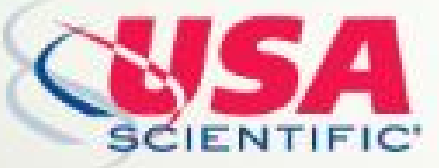

To subscribe to $R N A$ go to:

http://rnajournal.cshlp.org/subscriptions 